\title{
Survival after valve replacement for aortic stenosis: Implications for decision making
}

\author{
Tomislav Mihaljevic, MD, ${ }^{a}$ Edward R. Nowicki, MD, ${ }^{a}$ Jeevanantham Rajeswaran, MSc, ${ }^{\text {b }}$ Eugene H. Blackstone, MD, ${ }^{\mathrm{a}, \mathrm{b}}$
} Luigi Lagazzi, MD, ${ }^{a}$ James Thomas, MD, ${ }^{c}$ Bruce W. Lytle, MD, ${ }^{a}$ and Delos M. Cosgrove, $\mathrm{MD}^{\mathrm{a}}$

Supplemental material is available online.
From the Departments of Thoracic and Cardiovascular Surgery, ${ }^{\mathrm{a}}$ Quantitative Health Sciences, ${ }^{\mathrm{b}}$ and Cardiovascular Medicine, ${ }^{\mathrm{c}}$ Cleveland Clinic, Cleveland, Ohio.

This study was supported in part by the Kenneth Gee and Paula Shaw, PhD, Chair in Heart Research.

Presented at the 87th Annual Meeting of the American Association for Thoracic Surgery, Washington, DC, May 5 to 9, 2007.

Received for publication May 2, 2007; revisions received Nov 29, 2007; accepted for publication Dec 18, 2007.

Address for reprints: Tomislav Mihaljevic, MD, Department of Thoracic and Cardiovascular Surgery, Cleveland Clinic, 9500 Euclid Avenue/Desk F24, Cleveland, OH 44195 (E-mail: mihaljt@ccf.org).

J Thorac Cardiovasc Surg 2008;135:1270-9 $0022-5223 / \$ 34.00$

Copyright $\odot 2008$ by The American Association for Thoracic Surgery

doi:10.1016/j.jtcvs.2007.12.042
Objective: Recommendations for aortic valve replacement in severe aortic stenosis are based primarily on the presence of symptoms. However, the onset of symptoms is often insidious, potentially leading to delayed intervention and suboptimal results. Identifying factors that reduce the survival of patients undergoing aortic valve replacement could lead to revised treatment guidelines and improved outcomes.

Methods: We conducted a single-center observational clinical study of 3049 patients with aortic stenosis who underwent native aortic valve replacement with a single type of bioprosthesis. The primary end point was all-cause mortality from the date of operation. Multivariable analysis of risk factors for death was performed in the multiphase hazard function domain.

Results: The presence of severe left ventricular hypertrophy at operation, which preceded symptoms in $17 \%$ of patients, was associated with decreased survival. This effect was magnified by the severity of aortic stenosis $(P=.02)$ and use of small prostheses $(P=.01)$. The presence of left ventricular dysfunction reduced survival $(P=$ $.0003)$. Although older age was a risk factor for death $(P<.0001)$, elderly patients had survival comparable to their age, race, and sex-matched cohorts, whereas younger patients had worse than expected survival that was further diminished with insertion of a small prosthesis $(P=.01)$.

Conclusion: To optimize survival, earlier aortic valve replacement should be considered even in asymptomatic patients before severe left ventricular hypertrophy or dysfunction develops. In younger patients, the largest possible prosthesis should be implanted to minimize residual gradient; in elderly patients, complex operations just to insert larger prostheses should be avoided.

A ortic valve replacement (AVR) is recommended for symptomatic patients with severe aortic stenosis to improve symptoms and increase survival. ${ }^{1}$ However, the onset of symptoms may be insidious, difficult to elicit, ${ }^{2}$ and therefore unreliable in isolation for decision making. As a result, AVR may be delayed until the disease is in advanced stages, precluding optimal survival benefit. We postulate that survival after AVR is adversely influenced by preoperative severity of aortic stenosis and its resultant secondary effects on left ventricular (LV) structure and function.

Advances in prosthesis technology and improved operative and postoperative management have decreased the risks of valve replacement; thus, operation should be considered before the secondary effects on LV structure and function from severe aortic stenosis decrease the benefit of valve replacement. To optimize survival after AVR, we investigated these non-symptom factors, specifically, the detrimental effects on survival of the complex interplay of severity of aortic stenosis, LV hypertrophy and dysfunction, age, and small prosthesis size, all of which may play a role in decision making, including the timing of operation. 


\section{Abbreviations and Acronyms \\ $\mathrm{AV}=$ aortic valve \\ $\mathrm{AVR}=$ aortic valve replacement \\ $\mathrm{EF}=$ ejection fraction \\ $\mathrm{LV}=$ left ventricular}

\section{Patients and Methods \\ Patients}

Between October of 1991 and January of 2004, 3049 patients underwent native AVR for aortic stenosis or mixed stenosis and regurgitation, with or without coronary artery bypass grafting. Excluded were patients with predominant aortic regurgitation rather than stenosis, infective endocarditis, and rheumatic or other causes of aortic valve (AV) disease, and those who underwent any other concomitant valvar or aortic surgery. To avoid confounding of results with prosthesis type and model, the study was limited to a single prosthesis: the Carpentier-Edwards Perimount stented bovine pericardial valve (Model 2700, Edwards Lifesciences Corp, Irvine, Calif), one of the most commonly implanted prosthetic AVs. These patients represent the most common spectrum of surgery for AV stenosis in developed countries.

Preoperative patient characteristics, detailed echocardiographic variables, and intraoperative data were retrieved from the Cardiovascular Information Registry, a database maintained concurrently with patient care, and the Echocardiography Database (Table E1). Both have been approved for use in research by the institutional review board, with patient consent waived. Of the 3049 patients, 2859 (94\%) had moderately severe or severe aortic stenosis and 1980 (65\%) had pure aortic stenosis (Table E2).

\section{Preoperative Echocardiography}

Mean and peak instantaneous AV gradients were determined by Doppler measurements, and native AV orifice area was calculated by the continuity method. ${ }^{3} \mathrm{LV}$ mass was calculated from enddiastolic LV septal and posterior wall thicknesses, and internal dimension was calculated by the formula validated by Devereux and colleagues. ${ }^{4} \mathrm{LV}$ function was graded qualitatively as follows: ejection fraction (EF) $50 \%$ or greater, none; $\mathrm{EF} 40 \%$ to $49 \%$, mild; EF $35 \%$ to $39 \%$, moderate; EF $26 \%$ to $34 \%$, moderately severe; and EF $25 \%$ or less, severe. We previously demonstrated the prognostic sensitivity of this grading method. ${ }^{5}$

\section{Operative Technique}

AVR was performed on cardiopulmonary bypass at normothermia or mild hypothermia. Antegrade and retrograde cold blood cardioplegia for myocardial protection was routine. Intraoperative transesophageal echocardiography was used to confirm diagnoses and assess prosthesis function.

\section{Prosthesis Size}

Prosthesis size was defined in terms of the geometric internal orifice diameter (in millimeters) corresponding to the manufacturer's label size. ${ }^{6}$ Patient-prosthesis size was expressed as standardized orifice size (prosthesis-patient $Z$ value), the number of standard deviations by which the internal orifice diameter deviated from the mean nor- mal aortic anulus diameter for the patient's body surface area. ${ }^{6,7}$ Because a single-valve model was studied, these $Z$ values are comparable to projected orifice area estimates.

\section{End Point}

The study end point was all-cause mortality from the date of operation. Patients were routinely followed 2, 5, 10, and 15 years after AVR. These active follow-up data were supplemented by Social Security Death Index data with a common closing date of October 25, $2005 .{ }^{8,9}$ In all, 29 patients $(0.95 \%)$ were untraced beyond hospital discharge and 126 patients (4\%) did not have a Social Security number for supplemental passive follow-up. Follow-up was $5.1 \pm 3.2$ years (median 4.5 years), and 15,481 patient-years of data were available for analysis; $25 \%$ of living patients were followed more than 7.6 years, and $10 \%$ were followed more than 10 years. Survival was estimated nonparametrically by the Kaplan-Meier method and parametrically by a multiphase hazard model. ${ }^{10}$ Parametric modeling was used to resolve the number of phases of instantaneous risk of death (hazard function) and to estimate shaping parameters. (For additional details, see http://www.clevelandclinic.org/heartcenter/ hazard.)

Reference population survival estimates were generated from equations for the US Life Tables for each patient according to age, race, and sex. These were averaged overall and within subgroups of patients.

\section{Data Analysis}

To better understand the interplay of AV stenosis, LV structure and function, age, and prosthesis size, we performed an ordered sequence of analyses, with extensive exploration of interactions, to build a model of mortality (Tables E1 and E2 show the variables). Although we assumed that sporadic missing values for variables were missing at random and used mean value imputation, we incorporated missing-value indicator variables for these to adjust the analysis for possible systematic biases; we found none.

Variable selection. Multivariable analyses were performed in the multiphase hazard function domain. Variable selection, with a $P$ value criterion for retention of variables in the model of .05 , used bootstrap aggregation (bagging) from automated analysis of 500 bootstrap data sets. ${ }^{11,12}$ Variables appearing in $50 \%$ or more of the models were retained as risk factors.

Additional analyses. Linear regression was used to identify correlates of native AV orifice area, LV mass index, and prosthesispatient size, and logistic regression was used for LV function.

Presentation. Continuous variables are summarized as means \pm standard deviations and as 15 th, 50th (median), and 85 th percentiles, and categoric data are summarized as frequencies and percentages. Analyses were performed using SAS version 9.1 (SAS, Inc, Cary, $\mathrm{NC}$ ). Uncertainty is expressed by $68 \%$ confidence limits equivalent to \pm 1 standard error.

\section{Results \\ Overall Survival}

Non-risk-adjusted survival estimates for the entire group at 30 days, 6 months, and 1, 5, and 10 years were 97\%, 93\%, $91 \%, 75 \%$, and $47 \%$, respectively (Figure E1, $A$ ). Risk of death was highest immediately after operation (Figure E1, B), decreased to its nadir approximately 1 year 
TABLE 1. Incremental risk factors for death after aortic valve replacement

\begin{tabular}{|c|c|c|c|}
\hline Factor & Coefficient \pm SD & $\boldsymbol{P}$ & Reliability $(\%)^{a}$ \\
\hline \multicolumn{4}{|l|}{ Early hazard phase } \\
\hline Older age $\mathrm{b}^{\mathrm{b}}$ & $0.29 \pm 0.11$ & .01 & 45 \\
\hline Dilated left ventricle & $0.46 \pm 0.19$ & .01 & 59 \\
\hline \multicolumn{4}{|l|}{ Smaller prosthesis size } \\
\hline Prosthesis-patient $Z$ value $^{\mathrm{c}}$ & $0.026 \pm 0.0073$ & .0005 & 90 \\
\hline Prosthesis-patient $Z$ value $^{\mathrm{d}}$ & $0.054 \pm 0.021$ & .01 & 90 \\
\hline Calcified ascending aorta & $0.36 \pm 0.14$ & .01 & 66 \\
\hline Left main stenosis $(\geq 70 \%)$ & $0.63 \pm 0.21$ & .003 & 95 \\
\hline LCx stenosis $(>0 \%)$ & $0.30 \pm 0.15$ & .04 & 95 \\
\hline Hypertension & $0.51 \pm 0.19$ & .008 & 82 \\
\hline Insulin-treated diabetes & $0.53 \pm 0.21$ & .01 & 62 \\
\hline Renal disease & $1.2 \pm 0.20$ & $<.0001$ & 100 \\
\hline Lower creatinine clearance $\mathrm{e}^{\mathrm{e}}$ & $-0.45 \pm 0.14$ & .002 & 100 \\
\hline Earlier date of operation & $-0.081 \pm 0.021$ & .0001 & 59 \\
\hline \multicolumn{4}{|l|}{ Late hazard phase } \\
\hline Older age & & & 100 \\
\hline $\mathrm{Age}^{\mathrm{b}}$ & $0.86 \pm 0.15$ & $<.0001$ & \\
\hline AV (native) orifice area ${ }^{f}$ & $2.9 \pm 1.2$ & .01 & 79 \\
\hline Interaction: age/AV orifice area $^{g}$ & $-0.56 \pm 0.25$ & .02 & \\
\hline Larger LV mass index ${ }^{\mathrm{h}}$ & $0.22 \pm 0.104$ & .03 & 72 \\
\hline Interaction: LV mass index/AV (native) orifice area ${ }^{i}$ & $-0.49 \pm 0.20$ & .01 & \\
\hline Smaller prosthesis-patient size $(Z \text { value })^{\mathrm{j}}$ & $0.22 \pm 0.104$ & .03 & 90 \\
\hline Interaction: prosthesis-patient Z-value/age ${ }^{\mathrm{k}}$ & $-0.060 \pm 0.024$ & .01 & \\
\hline Interaction: prosthesis-patient Z-value/LV mass index & $0.0505 \pm 0.0204$ & .01 & \\
\hline LV dysfunction ${ }^{\mathrm{m}}$ & $0.33 \pm 0.095$ & .0006 & 92 \\
\hline Higher NYHA functional class ${ }^{n}$ & $0.23 \pm 0.081$ & .005 & 70 \\
\hline More previous cardiac operations & $0.16 \pm 0.077$ & .04 & 46 \\
\hline Preoperative atrial fibrillation & $0.37 \pm 0.13$ & .005 & 68 \\
\hline Ventricular arrhythmia & $0.29 \pm 0.12$ & .01 & 74 \\
\hline LMT disease $(>0 \%)$ & $0.17 \pm 0.089$ & .05 & 97 \\
\hline Higher MV regurgitation grade ${ }^{0}$ & $-0.53 \pm 0.19$ & .006 & 86 \\
\hline Insulin-treated diabetes & $0.54 \pm 0.14$ & .0002 & 98 \\
\hline Smoking & $0.19 \pm 0.081$ & .02 & 74 \\
\hline History of peripheral arterial disease & $0.29 \pm 0.086$ & .0006 & 77 \\
\hline Higher BUN & $0.012 \pm 0.0035$ & .0005 & 100 \\
\hline Lower creatinine clearance ${ }^{\mathrm{e}}$ & $-0.28 \pm 0.12$ & .02 & 100 \\
\hline Lower hematocrit $^{p}$ & $-0.52 \pm 0.19$ & .008 & 73 \\
\hline
\end{tabular}

$A V$, Aortic valve; $B U N$, blood urea nitrogen; $L C X$, left circumflex; $L M T$, left main trunk; $L V$, left ventricular; $M V$, mitral valve; $N Y H A$, New York Heart Association. ${ }^{a}$ Percent of times factor appeared in 500 bootstrap analyses. ${ }^{b}$ Exp(age/50), exponential transformation. ${ }^{c}$ Exp(prosthesis-patient $Z$ value), exponential transformation. ${ }^{\mathrm{d}}\left(1 /\right.$ exponential transformation of prosthesis-patient $Z$ value), inverse transformation. ${ }^{\mathrm{e}} \mathrm{Ln}$ (creatinine clearance), logarithmic transformation. ${ }^{\mathrm{f}}(\mathrm{AV}$ orifice area $)^{2}$, squared transformation. ${ }^{9}$ Interaction: exp(age/50)/(AV orifice area $)^{2}$. h(LV mass index/125) ${ }^{2}$, squared transformation. Interaction: $(A V$ orifice area $)^{2} /(\text { LV mass index/125) })^{2} .{ }^{j}(1 /$ exponential transformation of prosthesis-patient $Z$ value $)$, inverse transformation. ${ }^{k}(1 /$ exponential transformation of prosthesis-patient $Z$ value)/exp(age/50). '(1/exponential transformation of prosthesis-patient $Z$ value)/(LV mass index/125) ${ }^{2}$. $\mathrm{LV}$ dysfunction grades $>$ none, binary variable. ${ }^{\mathrm{n}}\left(\mathrm{NYHA}\right.$ class I/II vs II/IV), binary variable. ${ }^{\circ}\left(1 / \mathrm{MV}\right.$ regurgitation+1), inverse transformation. ${ }^{\mathrm{p}}\left(\right.$ Hematocrit/40) ${ }^{2}$, squared transformation.

postoperatively (early hazard phase), and then gradually increased (late hazard phase). From approximately 2 years after valve replacement, survival was similar to that of matched population estimates.

\section{Risk Factors}

Risk factors for death early after operation $(\sim<1$ year) included older age, LV dilatation, smaller prosthesis size, calcified ascending aorta, and earlier date of operation
(Table 1). Risk factors for late death $(\sim>1$ year) included similar factors, but specifically older age, greater degree of aortic stenosis, greater LV mass index, smaller standardized prothesis-patient size, interactions among these 4 factors, and, in addition, LV dysfunction and advanced symptoms (moderate to severe vs none or mild; Figure 1, $A$ ). Risk factors associated with advanced symptoms included calcific aortic stenosis and severe LV dysfunction (Table E3). More recent patients were less likely to have advanced symptoms. 

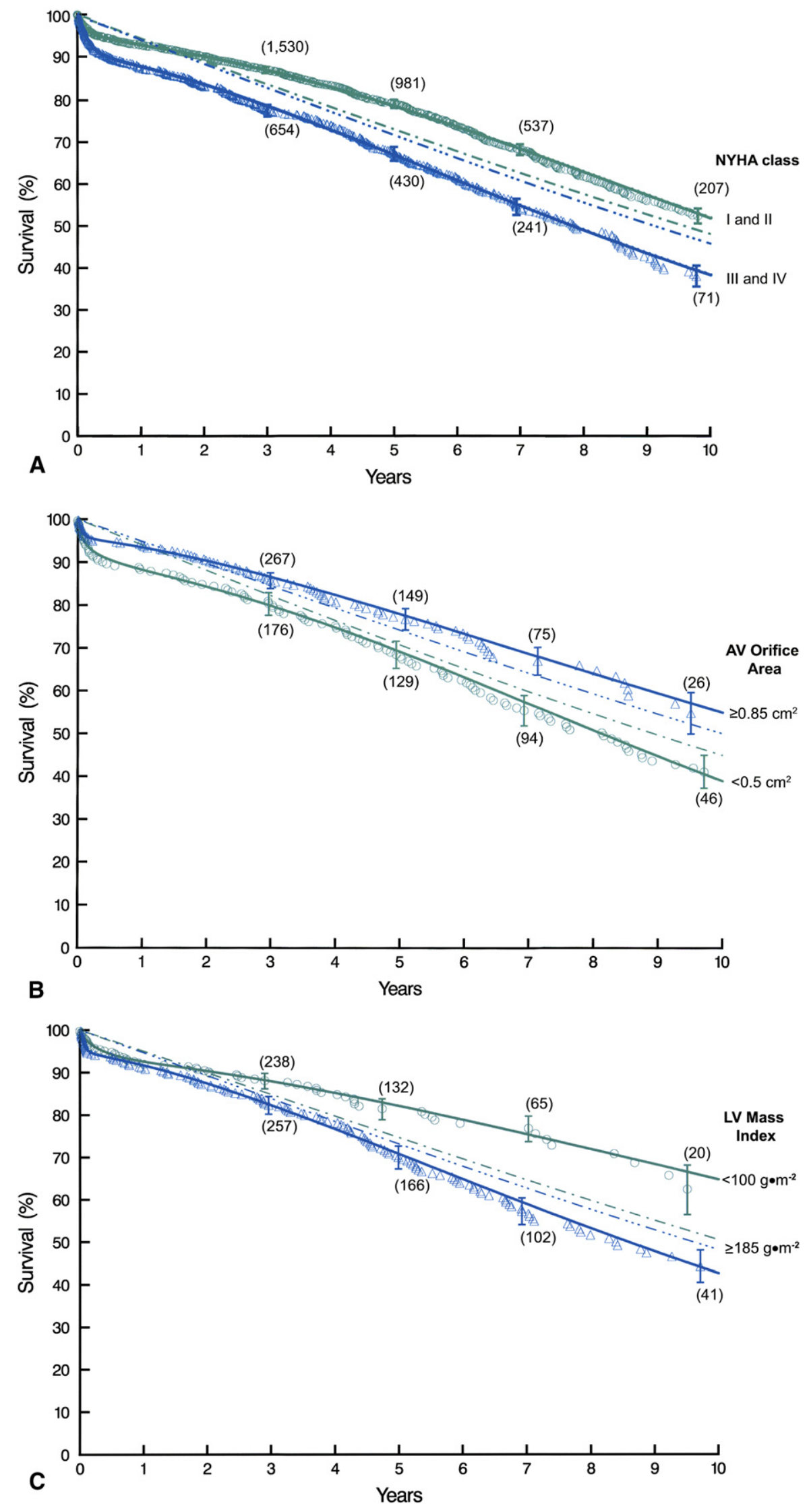

Figure 1. Survival after AVR according to primary risk factors. Each symbol represents a death, vertical bars are $68 \%$ confidence limits equivalent to \pm 1 standard error, and numbers in parentheses are patients remaining at risk. Solid lines are parametric estimates. Dashed lines with corresponding color represent corresponding survival of an age, race, and sexmatched population. A, Severity of symptoms expressed as New York Heart Association classes I and II versus III and IV. Figure includes all patients in study. B, Severity of aortic stenosis expressed as native AV orifice area. For clarity, only patients with extreme values are depicted, with the remaining values between ( $15 \%$ had orifice area $\geq$ $0.85 \mathrm{~cm}^{2}$ and $9.3 \%$ had orifice area $<0.5$ $\mathrm{cm}^{2}$ ). C, Severity of LV hypertrophy, expressed as LV mass index. For clarity, only patients with extreme values are depicted, with the remaining values between $\left(15 \%\right.$ had mass $<100 \mathrm{~g} / \mathrm{m}^{2}$ and $15 \%$ had mass $\geq 185 \mathrm{~g} / \mathrm{m}^{2}$ ). D, LV dysfunction. All patients are depicted. $E$, Age. All patients are depicted. F, Prosthesis size, expressed as prosthesispatient size ( $Z$ value). For clarity, only patients with extreme values are depicted, with the remaining values between $(15 \%$ had $Z$ values $>0.5$ and $13 \%$ had $Z$ values $\leq-1.5)$. NYHA, New York Heart Association. 


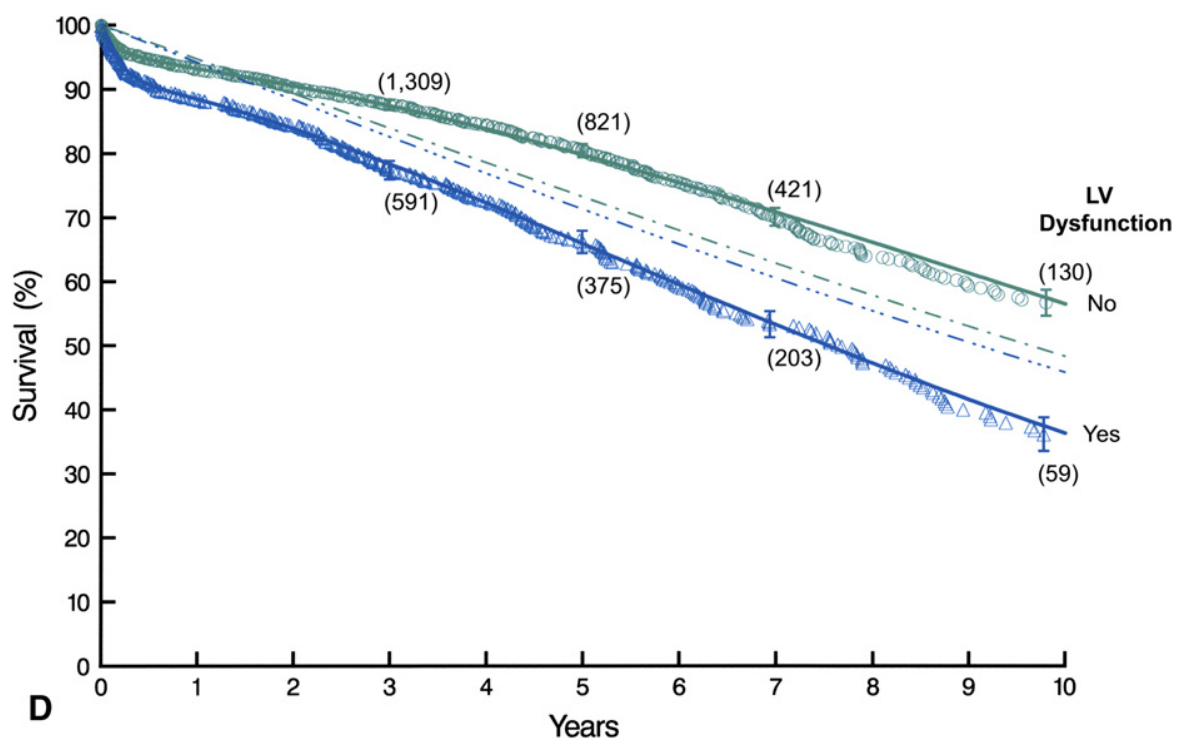

Figure 1. (Continued)

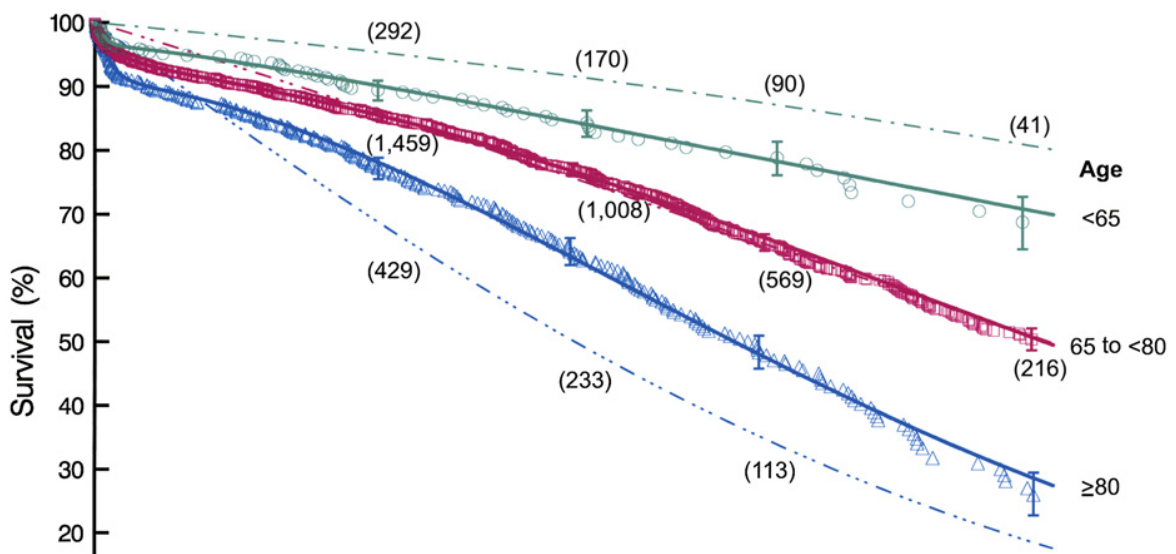

(25)

E
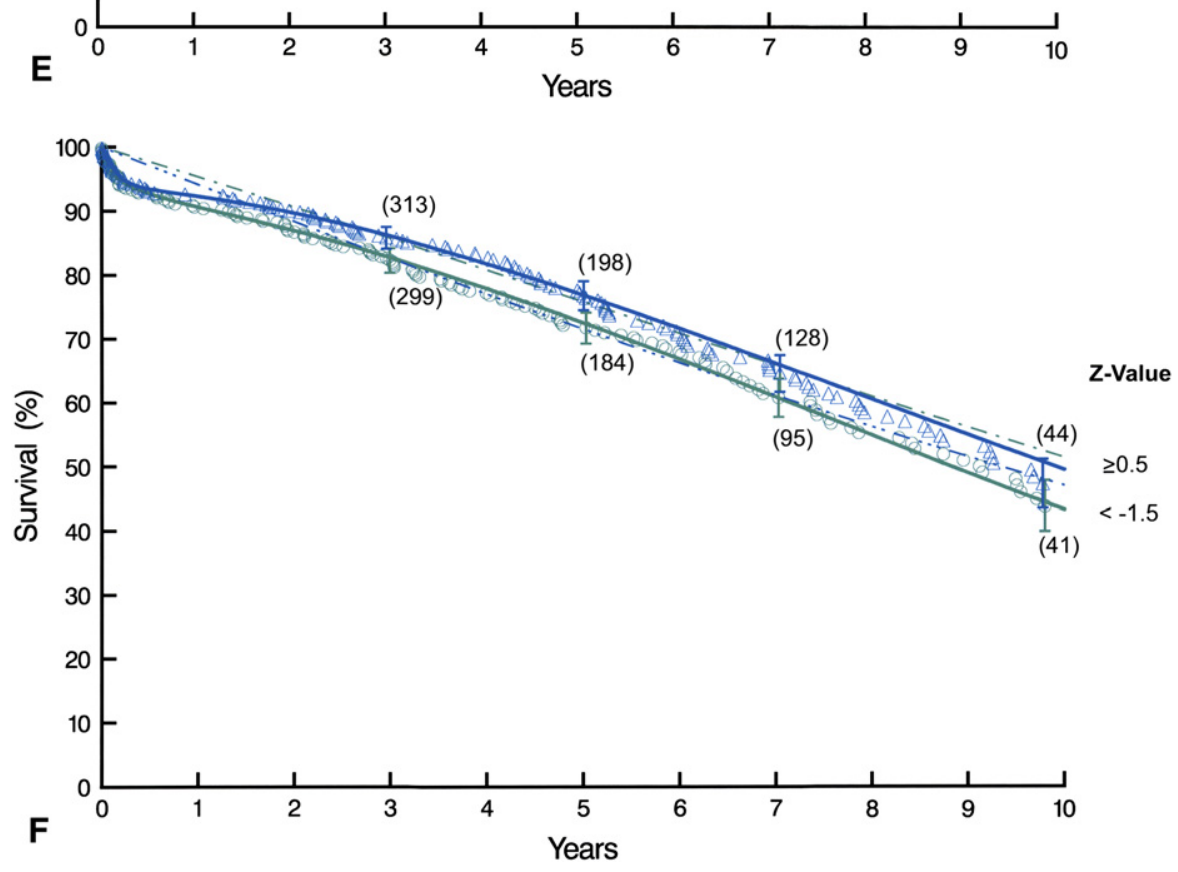

1274 The Journal of Thoracic and Cardiovascular Surgery • June 2008 

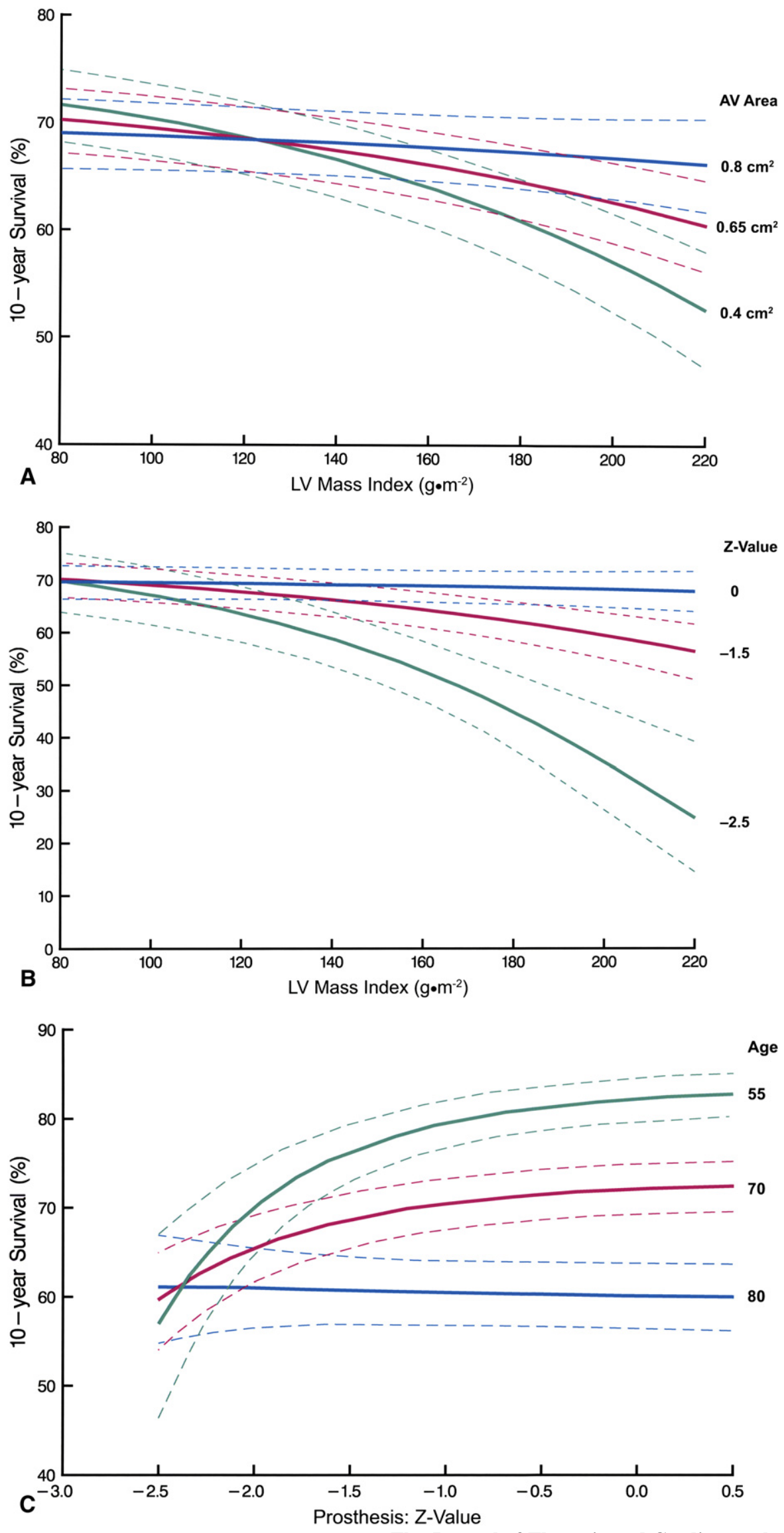

The Journal of Thoracic and Cardiovascular Surgery • Volume 135, Number 61275
Figure 2. Nomograms of 10 -year survival after AVR from the multivariable analysis of death (Table 1). To produce these risk-adjusted depictions, values for the following variables were held constant (unless depicted in the graph): age, 73 years; no mitral regurgitation; AV orifice area, $0.7 \mathrm{~cm}^{2}$; New York Heart Association functional class I/II; date of operation, January 2004; LV mass index, $135 \mathrm{~g} / \mathrm{m}^{-2}$; no ventricular arrhythmia; no previous cardiac operation; left main stenosis, $\geq \mathbf{7 0} \%$; left circumflex stenosis, $>0 \%$; smoker; peripheral arterial disease; hypertensive; nondiabetic; no renal disease; blood urea nitrogen, 19 $\mathrm{mg} / \mathrm{dL}^{-1}$; creatinine clearance, $65 \mathrm{~mL}$ / $\min ^{-1}$; hematocrit, $38 \%$. Solid lines are parametric estimates, and dashed lines are asymmetric $68 \%$ confidence limits. Note the expanded vertical axes. A, LV mass index and AV orifice area. B, Prosthesis-patient $Z$ value and $L V$ mass index. C, Prosthesis-patient $Z$ value and age. 


\section{Unadjusted Associations with Mortality}

The non-risk-adjusted association of the 5 primary risk factors with mortality (severity of aortic stenosis, LV hypertrophy, LV function, age, and prosthesis-patient size) was explored as follows:

Severity of aortic stenosis. Greater degree of severity of aortic stenosis at operation was associated with increased risk of late mortality (Figure 1,B). Patients with larger valve area experienced better survival than their population counterparts; those with smaller valve area had poorer early survival that was less than that of their population counterparts. Patients with small valves were older and more likely to have bicuspid morphology with LV hypertrophy and had more severe LV dysfunction (Table E4).

Left ventricular hypertrophy. Patients with severe LV hypertrophy had higher late mortality that was distinctly worse than that of their population counterparts (Figure 1, $C)$. They tended to be younger men with more severe aortic stenosis and advanced symptoms (Table E5). A large proportion of asymptomatic patients (145/303 [48\%]) and mildly symptomatic patients $(616 / 1262$ [49\%]) had an LV mass index greater than the upper limit of normal for men $(\geq 135 \mathrm{~g} /$ $\mathrm{m}^{-2}$ ). Even when LV mass index was $185 \mathrm{~g} / \mathrm{m}^{-2}$ or greater, $17 \%$ of patients were asymptomatic and $14 \%$ of patients were mildly symptomatic.

Left ventricular function. Patients with any LV dysfunction had considerably worse survival than those with normal LV function and their population counterparts (Figure 1,D). They had more severe aortic stenosis, but lower peak aortic gradient, larger LV volumes, and greater degree of atrioventricular valve regurgitation (Table E6). Further, some degree of LV dysfunction had already occurred in 67 of 352 asymptomatic patients (19\%) and in 389 of 1507 mildly symptomatic patients (26\%).

Age. Although older age was a risk factor for mortality, survival of younger patients was less than that expected of their population counterparts (Figure 1,E). In contrast, survival of elderly patients exceeded that of their counterparts after the initial year of higher mortality. Patients younger than age 65 years, however, constituted only $14 \%$ of cases.

Prosthesis-patient size. Patients with prostheses most disproportionally small for body size had early survival similar to those with the largest size, but slightly worse late survival (Figure 1,F). They were older and had more severe aortic stenosis, tricuspid morphology, and less hypertrophy (Table E7).

\section{Interplay of Risk Factors}

Native AV orifice area, LV mass index, age, and prosthesispatient size were not found to be additive (incremental) risk factors but to interact with one another to modulate risk (Table 1). As the degree of both aortic stenosis and LV hypertrophy increased, survival was greatly reduced (Figure 2, A).
Survival was also diminished when a small prosthetic valve was used in patients with severe LV hypertrophy (Figure 2, $B)$. This effect was more pronounced in younger than in older patients, particularly below prosthesis-patient $Z$ values of approximately -1.5 (Figure 2,C). Figure E2 illustrates more fully the interplay of these 4 factors, with diminishing order of effect on survival by age, followed by LV mass, native AV size, and prosthesis-patient size. In contrast with these 4 factors, the presence of LV dysfunction was an incremental risk factor only and did not interact with any other factor.

\section{Discussion \\ Principal Findings}

Our results demonstrate that survival of patients with aortic stenosis after AVR is primarily influenced by severity of the stenosis and severity of LV hypertrophy and dysfunction at operation. Although age was the strongest risk factor, survival of elderly patients was better than that of their age, race, and sex-matched population counterparts, whereas survival of younger patients was worse than expected, particularly in those with severe LV hypertrophy in whom a small prosthesis was implanted.

\section{Severity of Aortic Stenosis}

More severe degrees of aortic stenosis were associated with worse long-term survival, particularly when severe LV hypertrophy was present. Chronic pressure overload in patients with aortic stenosis results in concentric LV hypertrophy. Although this represents a physiologic compensatory mechanism, severe LV hypertrophy may have deleterious effects on the LV, including increased sensitivity to ischemia (even in the absence of coronary artery disease) with consequent systolic or diastolic dysfunction. ${ }^{13,14}$

\section{Left Ventricular Hypertrophy}

Although large LV mass has been associated with increased in-hospital mortality of patients undergoing AVR for aortic stenosis ${ }^{15}$ our study provides evidence that links severe LV hypertrophy to decreased long-term survival. This suboptimal result of AVR is likely the result of irreversible myocardial changes and fibrosis associated with severe LV hypertrophy. ${ }^{16,17} \mathrm{LV}$ reverse remodeling may be delayed by a small prosthesis with high residual pressure gradient, emphasizing the need for using the largest possible prosthesis in patients with severe LV hypertrophy.

\section{Left Ventricular Dysfunction}

In advanced stages of disease, the hypertrophic process may become inadequate to keep systolic wall stress within normal limits, causing a decrease in $\mathrm{EF} .^{18} \mathrm{LV}$ dysfunction was a strong predictor of worse long-term survival in our study, correlating with findings from previous studies. ${ }^{19}$ 


\section{Age}

Worse survival of younger patients compared with their age, race, sex-matched counterparts likely reflects the nature of aortic stenosis in these adults. A large proportion had bicuspid aortic stenosis (Figure E3), a congenital anomaly of not only the valve but also the proximal arterial tree that causes a chronic, sustained systolic pressure load early in life, unlike senile aortic stenosis. ${ }^{20}$ We speculate that the early onset of myocardial hypertrophy early in life and chronicity of myocardial changes are responsible for late myocardial dysfunction, even after successful AVR.

Many elderly patients with severe symptomatic aortic stenosis are not referred for surgery because of their age, although improvement in postoperative quality of life of octogenarians after AVR is of similar magnitude to that of younger patients. ${ }^{21,22}$ Survival of elderly patients in our study was comparable to that of their age, race, and sexmatched cohorts, which is in accord with previous findings. ${ }^{6,23,24}$ These results suggest that AVR should be strongly considered in all patients with severe aortic stenosis, irrespective of age.

\section{Prosthesis Size}

Numerous single-institution studies have identified prosthesis-patient mismatch as a risk factor affecting survival after AVR for aortic stenosis. ${ }^{25-32}$ However, these studies were conducted on relatively few patients with various types of aortic prostheses, resulting in heterogeneous study populations. In this study, we used a single type of prosthesis to avoid confounding of prosthesis-patient size with prosthesis type and model. The deleterious effect of small prosthesispatient size in younger patients was absent in elderly patients, although the majority of small prostheses are implanted in the elderly. This suggests that patient-prosthesis size has clinical relevance (Figure E4); however, the effect was mild.

\section{Limitations}

This was a single-center observational clinical study on valve replacement for the spectrum of severe aortic stenosis. However, the experience is large, as is the number of variables available to analyze these insufficiently studied aspects of treating aortic stenosis. Although asymptomatic patients were a minority in this study, this is the largest cohort of asymptomatic patients with aortic stenosis studied to date.

\section{Implications for Guidelines}

Current guidelines for treating severe aortic stenosis identify the onset of symptoms as the critical point for AVR, although symptoms are often subtle and not apparent to the physician on routine examination. ${ }^{1,33}$ Our study underscores this point in that approximately $50 \%$ of patients with mild or no symptoms by routine history had developed severe LV hypertrophy, and an important percentage of these had shown signs of LV dysfunction before AVR. These findings suggest that relying on symptoms alone in therapeutic decision making is inadequate. Thus, AVR should be performed before severe LV hypertrophy and dysfunction develop. In younger patients, the largest possible prosthesis should be implanted to minimize the residual gradient. In elderly patients, complex operations just to insert larger prostheses should be avoided.

\section{References}

1. Bonow RO, Carabello BA, Kanu C. de Leon AC Jr, Faxon DP, Freed MD, et al. ACC/AHA 2006 guidelines for the management of patients with valvular heart disease: a report of the American College of Cardiology/American Heart Association Task Force on Practice Guidelines (writing committee to revise the 1998 Guidelines for the Management of Patients With Valvular Heart Disease). Circulation. 2006;114: e84-231.

2. Otto CM. Valvular aortic stenosis: disease severity and timing of intervention. J Am Coll Cardiol. 2006;47:2141-51.

3. Schiller NB, Shah PM, Crawford M, DeMaria A, Devereux R, Feigenbaum $\mathrm{H}$, et al. Recommendations for quantitation of the left ventricle by two-dimensional echocardiography. American Society of Echocardiography Committee on Standards, Subcommittee on Quantitation of Two-Dimensional Echocardiograms. $J$ Am Soc Echocardiogr. 1989;2:358-67.

4. Devereux RB, Alonso DR, Lutas EM, Gottlieb GJ, Campo E, Sachs I, et al. Echocardiographic assessment of left ventricular hypertrophy: comparison to necropsy findings. Am J Cardiol. 1986;57:450-8.

5. Watanabe J, Thamilarasan M, Blackstone EH, Thomas JD, Lauer MS. Heart rate recovery immediately after treadmill exercise and left ventricular systolic dysfunction as predictors of mortality: the case of stress echocardiography. Circulation. 2001;104:1911-6.

6. Blackstone EH, Cosgrove DM, Jamieson WR, Birkmeyer NJ, Lemmer JH Jr, Miller DC, et al. Prosthesis size and long-term survival after aortic valve replacement. J Thorac Cardiovasc Surg. 2003;126: 783-96.

7. Capps SB, Elkins RC, Fronk DM. Body surface area as a predictor of aortic and pulmonary valve diameter. J Thorac Cardiovasc Surg. 2000; 119:975-82.

8. Boyle CA, Decoufle P. National sources of vital status information: extent of coverage and possible selectivity in reporting. Am J Epidemiol. 1990;131:160-8.

9. Newman TB, Brown AN. Use of commercial record linkage software and vital statistics to identify patient deaths. J Am Med Inform Assoc. 1997;4:233-7.

10. Blackstone EH, Naftel DC, Turner ME Jr. The decomposition of timevarying hazard into phases, each incorporating a separate stream of concomitant information. J Am Stat Assoc. 1986;81:615-24.

11. Breiman L. Bagging predictors. Machine Learning. 1996;24:123-40.

12. Blackstone EH. Breaking down barriers: helpful breakthrough statistical methods you need to understand better. J Thorac Cardiovasc Surg. 2001;122:430-9.

13. Gaasch WH, Zile MR, Hoshino PK, Weinberg EO, Rhodes DR, Apstein CS. Tolerance of the hypertrophic heart to ischemia. Studies in compensated and failing dog hearts with pressure overload hypertrophy. Circulation. 1990;81:1644-53.

14. Marcus ML, Doty DB, Hiratzka LF, Wright CB, Eastham CL. Decreased coronary reserve: a mechanism for angina pectoris in patients with aortic stenosis and normal coronary arteries. $N$ Engl J Med. 1982;307:1362-6.

15. Mehta RH, Bruckman D, Das S, Tsai T, Russman P, Karavite D, et al. Implications of increased left ventricular mass index on in-hospital outcomes in patients undergoing aortic valve surgery. J Thorac Cardiovasc Surg. 2001;122:919-28.

16. Krayenbuehl HP, Hess OM, Monrad ES, Schneider J, Mall G, Turina M. Left ventricular myocardial structure in aortic valve disease before, intermediate, and late after aortic valve replacement. Circulation. 1989;79: 744-55. 
17. Lund O, Erlandsen M, Dorup I, Emmertsen K, Flo C, Jensen FT. Predictable changes in left ventricular mass and function during ten years after valve replacement for aortic stenosis. J Heart Valve Dis. 2004;13:357-68.

18. Krayenbuehl HP, Hess OM, Ritter M, Monrad ES, Hoppeler H. Left ventricular systolic function in aortic stenosis. Eur Heart J. 1988; 9(Suppl E):19-23.

19. Aronow WS, Ahn C, Kronzon I, Nanna M. Prognosis of congestive heart failure in patients aged $>$ or $=62$ years with unoperated severe valvular aortic stenosis. Am J Cardiol. 1993;72:846-8.

20. Bauer M, Siniawski H, Pasic M, Schaumann B, Hetzer R. Different hemodynamic stress of the ascending aorta wall in patients with bicuspid and tricuspid aortic valve. $J$ Card Surg. 2006;21:218-20.

21. Iung B, Cachier A, Baron G, Messika-Zeitoun D, Delahaye F, Tornos P, et al. Decision-making in elderly patients with severe aortic stenosis: why are so many denied surgery? Eur Heart J. 2005;26:2714-20.

22. Olsson M, Janfjall H, Orth-Gomer K, Unden A, Rosenqvist M. Quality of life in octogenarians after valve replacement due to aortic stenosis. A prospective comparison with younger patients. Eur Heart J. 1996; 17:583-9.

23. Medalion B, Blackstone EH, Lytle BW, White J, Arnold JH, Cosgrove DM. Aortic valve replacement: is valve size important? J Thorac Cardiovasc Surg. 2000;119:963-74.

24. Medalion B, Lytle BW, McCarthy PM, Stewart RW, Arheart KL, Arnold JH, et al. Aortic valve replacement for octogenarians: are small valves bad? Ann Thorac Surg. 1998;66:699-706.

25. Pibarot P, Dumesnil JG, Cartier PC, Metras J, Lemieux MD. Patientprosthesis mismatch can be predicted at the time of operation. Ann Thorac Surg. 2001;71:S265-8.

26. Pibarot P, Dumesnil JG. Hemodynamic and clinical impact of prosthesis-patient mismatch in the aortic valve position and its prevention. J Am Coll Cardiol. 2000;36:1131-41.

27. Morris JJ, Schaff HV, Mullany CJ, Rastogi A, McGregor CG, Daly RC, et al. Determinants of survival and recovery of left ventricular function after aortic valve replacement. Ann Thorac Surg. 1993;56:22-30.

28. David TE, Feindel CM, Bos J, Sun Z, Scully HE, Rakowski H. Aortic valve replacement with a stentless porcine aortic valve. A six-year experience. J Thorac Cardiovasc Surg. 1994;108:1030-6.

29. He GW, Acuff TE, Ryan WH, Douthit MB, Bowman RT, He YH, et al. Aortic valve replacement: determinants of operative mortality. Ann Thorac Surg. 1994;57:1140-6.

30. He GW, Grunkemeier GL, Gately HL, Furnary AP, Starr A. Up to thirtyyear survival after aortic valve replacement in the small aortic root. Ann Thorac Surg. 1995;59:1056-62.

31. Adams DH, Chen RH, Kadner A, Aranki SF, Allred EN, Cohn LH. Impact of small prosthetic valve size on operative mortality in elderly patients after aortic valve replacement for aortic stenosis: does gender matter? J Thorac Cardiovasc Surg. 1999;118:815-22.

32. Cartier PC, Metras J, Dumesnil JG, Pibarot P, Lemieux M. Midterm follow-up of unstented biological valves. Semin Thorac Cardiovasc Surg. 1999;11:22-7.

33. Aikawa K, Otto CM. Timing of surgery in aortic stenosis. Prog Cardiovasc Dis. 2001;43:477-93.

\section{Discussion}

Dr Michael Mack (Dallas, Tex). You have performed a study that is potentially a landmark one and likely to change the landscape of the management of patients with critical aortic stenosis in the future. I believe this study is that important. First, similar to the study by Sarano in patients with asymptomatic mitral regurgitation, determining that an effective regurgitant orifice greater than 40 led to decreased survival, your study has defined some characteristics that may lead to earlier operative management of patients with aortic stenosis. Second, you have lent further clarity to the issue of patientprosthetic mismatch and perhaps saved some elderly patients from undergoing the added risk of a root-enlarging procedure. You conclude that LV hypertrophy, LV dysfunction, extremely severe aortic stenosis, older age, and a small prosthesis in younger patients decreased survival.
However, just as a movie critic needs to find something wrong with a movie to maintain credibility as a critic, I can't let you off scot-free. The positive aspects your study include the fact that it is a large study of more than 3000 patients who received a single type of valve with a mean follow-up of 5 years. A sophisticated statistical analysis (and thank you for the explanation of the $Z$ value) to minimize confounding variables lends further clarity to the data. However, this is not a population with isolated pure aortic stenosis, with $56 \%$ of the patients having undergone concomitant coronary bypass surgery and $35 \%$ of patients also having aortic regurgitation, factors known to affect outcomes. In addition, only $13 \%$ of the patients were actually asymptomatic, yet significant management conclusions are drawn from this group.

My specific questions are as follows. First, you defined a small prosthesis as a patient-prosthesis $Z$ value of -1.5 , which corresponds to 1.5 standard deviations below normal valve size for patient body surface area. Why did you pick that $Z$ value rather than perhaps 1 or 2 ?

Second, do you think that analysis of a population in whom more than half of the patients underwent coronary artery bypass grafting and one third of the patients had aortic regurgitation is valid for isolated pure aortic stenosis?

Third, we now make clinical decisions in patients with asymptomatic mitral regurgitation on the basis of an effective regurgitant orifice greater than 40. Surgeons are familiar with echocardiographic parameters of AV area, peak and mean gradients, jet velocity, and EF for making decisions. Should we now include an LV mass index of greater than 135 in men or greater than 100 in women as an indication for surgery in patients with critical aortic stenosis?

Four, as surgeons, we always want to know what to do different when we go home. We use the red, yellow, green charts to choose valve size now based on patient body surface area. Do your data mean that we should now ignore those color charts for elderly patients?

Fifth, you state that guidelines should be changed to recommend earlier AVR in asymptomatic patients, yet current guidelines, class IIb, already recommend AVR in asymptomatic patients with either an abnormal exercise test, likelihood of rapid progression based on age, calcification and coronary artery disease, or extremely severe aortic stenosis with a valve area of less than $0.6 \mathrm{~cm}^{2}$. How specifically would you recommend these current guidelines be changed?

Last, is it possible to come up with a patient management algorithm factoring in all the variables you have identified, including age, severity of aortic stenosis, LV dysfunction, LV mass index, to guide the timing of surgical interventions?

Dr Mihaljevic. The first question was why did we define a $Z$ value of -1.5 as a cutoff? That was not truly a deliberate decision. That was a result of an observation that by the $Z$ value of -1.5 and less, we noted the detrimental effects of the patient-prosthesis mismatch that truly affected the outcomes of our patients, in particular in those patients who had severe LV hypertrophy.

Your second question was whether we think that the analysis of the population in whom more than $50 \%$ of patients underwent coronary artery bypass grafting and one third of patients had severe aortic regurgitation is truly representative of typical patients with aortic stenosis. We think this is definitely the case. We purposely included these patients, because when patients present to a surgeon or a cardiologist with aortic stenosis, this is what typical patients look like. These are the patients who almost always have some degree of aortic regurgitation, but we were careful to exclude patients in whom the aortic regurgitation was a predominant pathology. Furthermore, it 
is just a reality that most of these patients will have coronary artery disease. The median age of patients in our study was 71 years, so those patients are most likely going to have coronary artery disease, and those are the patients we are going to see referred to us for aortic stenosis. We don't know if the coronary artery disease is present up front until they undergo a coronary angiogram. We are currently conducting a study in which we are particularly studying the effect of coronary artery disease in patients and their outcomes when they have severe aortic stenosis. Our preliminary findings show that the presence of coronary artery disease triggers the symptoms in patients with aortic stenosis much earlier in the course, and those patients almost never develop severe LV hypertrophy, because they become symptomatic much sooner in the course of their illness.

Your third question was regarding the echocardiographic parameters and whether we should use the LV mass index of greater than 135 as an indicator for surgery. I would absolutely concur with this statement. We as surgeons have to be familiar with new echocardiographic measurements, and just as you mentioned an example of mitral valve surgery, I think we have to pay particular attention to the ventricular effects of valvular heart disease. Ultimately all untreated patients with aortic stenosis die not because their aortic stenosis gets worse but because the effects of the aortic stenosis on the ventricle caused it to fail. The presence of severe LV hypertrophy should not any longer be viewed as a benign side effect of aortic stenosis, which will be reversed after we replace the AV, but a significant contributor in the pathology or bad outcomes of these patients even after a successful operation.

Your fourth question related to the sizes of the AV prostheses that should be used for elderly patients with severe aortic stenosis. As you saw from our presentation here, if we take a look at the entire population of patients with aortic stenosis and compare those who have severe patient-prosthesis mismatch with those who have prostheses that are larger than their anticipated AV area (standard AV area), their overall survival is fairly similar. When we look at patient-prosthesis mismatch, we have to look at the different ages of the patients undergoing operation, and in an elderly patient, the survival is truly not affected by a smaller prosthesis. So even implantation of a relatively small prosthesis was sufficient enough to relieve the gradient to the extent that it was beneficial to survival. If we take a look at our curves of survival of elderly patients, they benefited the most from AVR. Their survival is better than the expected survival of their matched cohorts, in contrast with our younger patients.

The fifth question is an important question about the current guidelines and class IIb indications for AVR for asymptomatic patients. In our opinion, some of these class IIb indications should be class I indications. For example, AV stenosis with an AV orifice area of -0.6 and a high gradient of 60 should truly be an indication for surgery based on our data. As you can see from the curves shown previously, patients with severe aortic stenosis and high gradients did poorly, even after initial successful surgery. If we take a critical look at the criteria that was used for the medical management, for example, of patients with asymptomatic aortic stenosis, all articles had a series with no more than 150 patients, with a follow-up that was not more than 1.5 to 2 years. The longest observed survival in patients with severe aortic stenosis who were asymptomatic and underwent medical management was 67\% 1-year event-free survival. The survival of patients who undergo surgery in the same condition is approximately $10 \%$ to $15 \%$ better after the first year. Obviously, they lack long-term follow-up because most of the patients develop symptoms anyhow and undergo surgery.

We hope that this article is going to be a significant contribution to influence a change in the guidelines for treatment of patients with asymptomatic aortic stenosis.

Your last question was, is it possible to come up with a patient management algorithm to include all the risk factors and come up with a new management scheme? Yes, absolutely. What we have to take into consideration now is no longer only the AV orifice area and gradients but also the degree of the LV hypertrophy, the age of the patients, and the degree of the LV dysfunction at the time of surgery, which most of us have been doing intuitively. 




A



Figure E1. Time -related survival after AVR. A, Survival. Each symbol represents a death, vertical bars $68 \%$ are confidence limits, and numbers in parentheses are patients remaining at risk. Solid line represents parametric estimates enclosed within $68 \%$ confidence limits. Dash-dot-dash line is survival for the age, race, and sex-matched population. B, Instantaneous risk of death (hazard function). Estimates are enclosed within $68 \%$ confidence limits. Dash-dot-dash line represents hazard function for the age, race, and sex-matched population. 

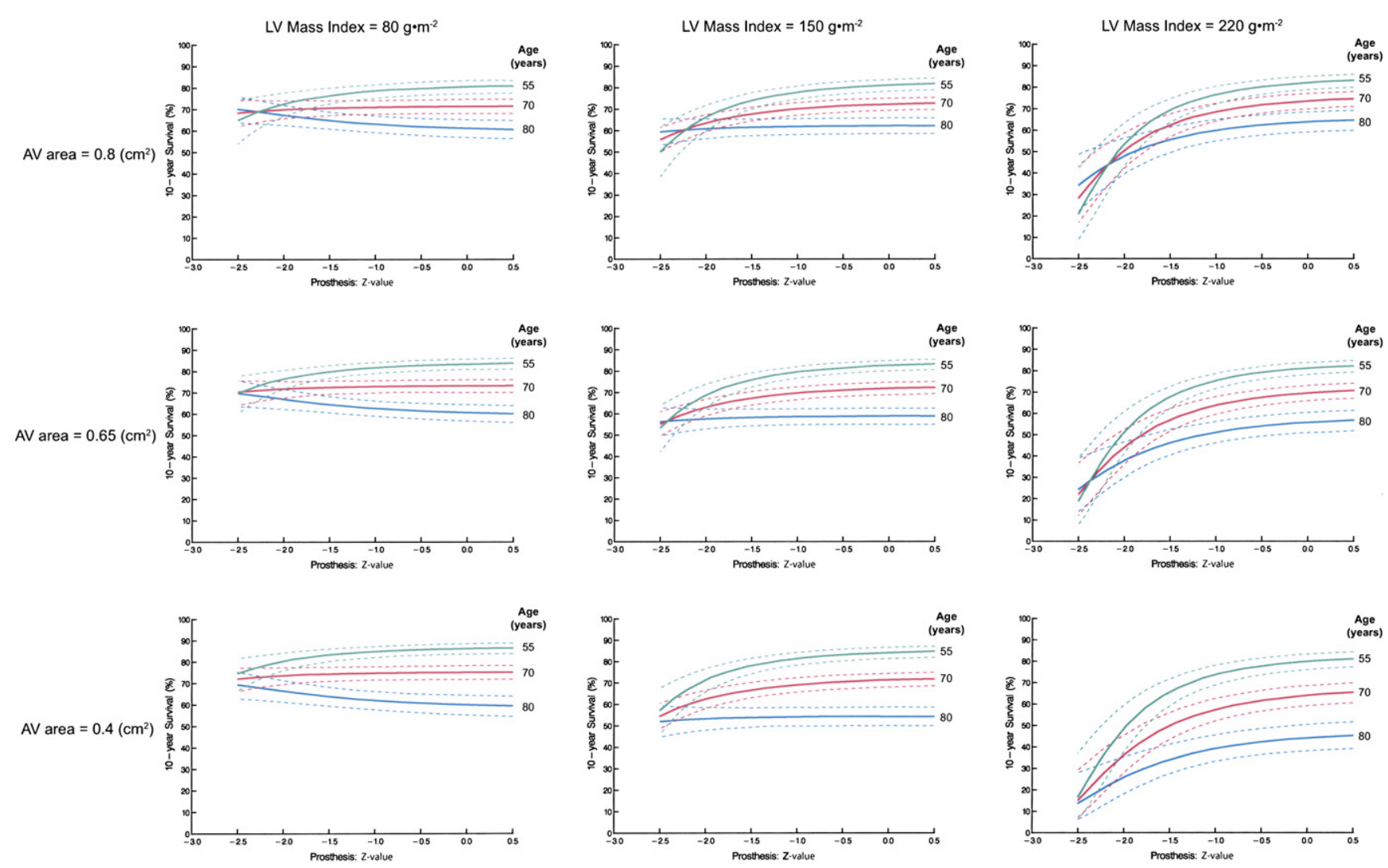

Figure E2. Ten -year survival after aortic value replacement according to interplay of primary risk factors. The 9 panels represent solutions to the multivariable equation by the indicated values of age, LV mass index, native AV size, and prosthesis-patient size ( $Z$ value). Solid lines represent parametric estimates enclosed within $68 \%$ confidence limits. 


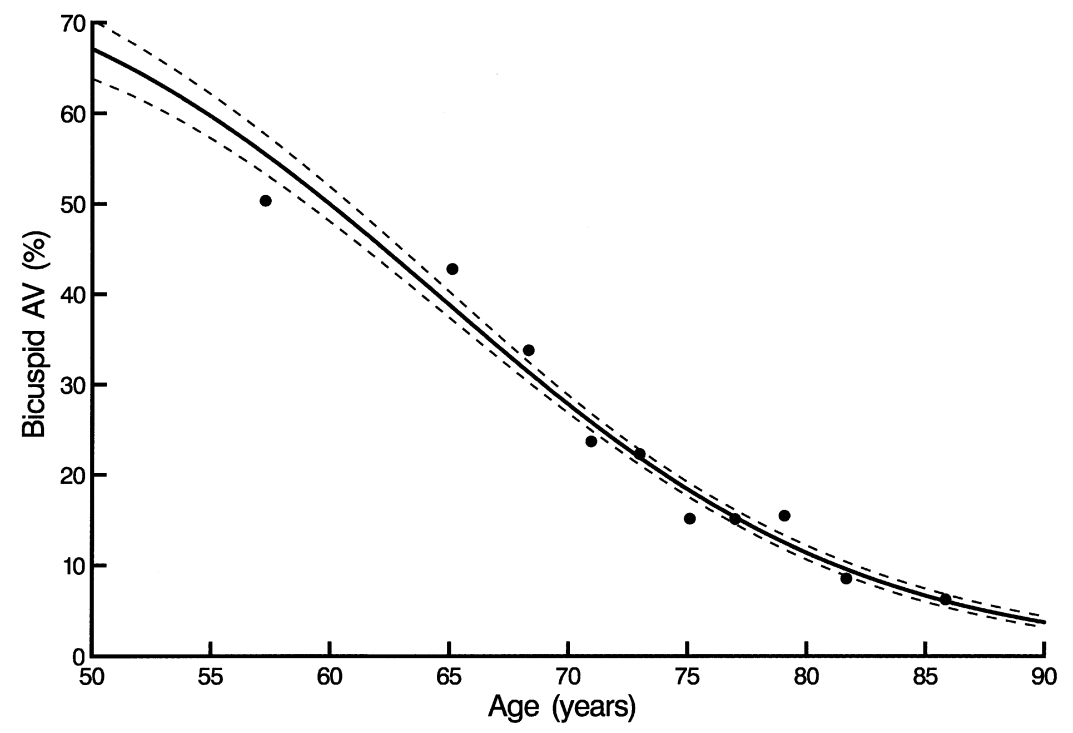

Figure E3. Bicuspid AV morphology according to age at $A V$ replacement. Closed circles represent percentage of patients with bicuspid valves in decile age ranges; solid line is a trend line. 


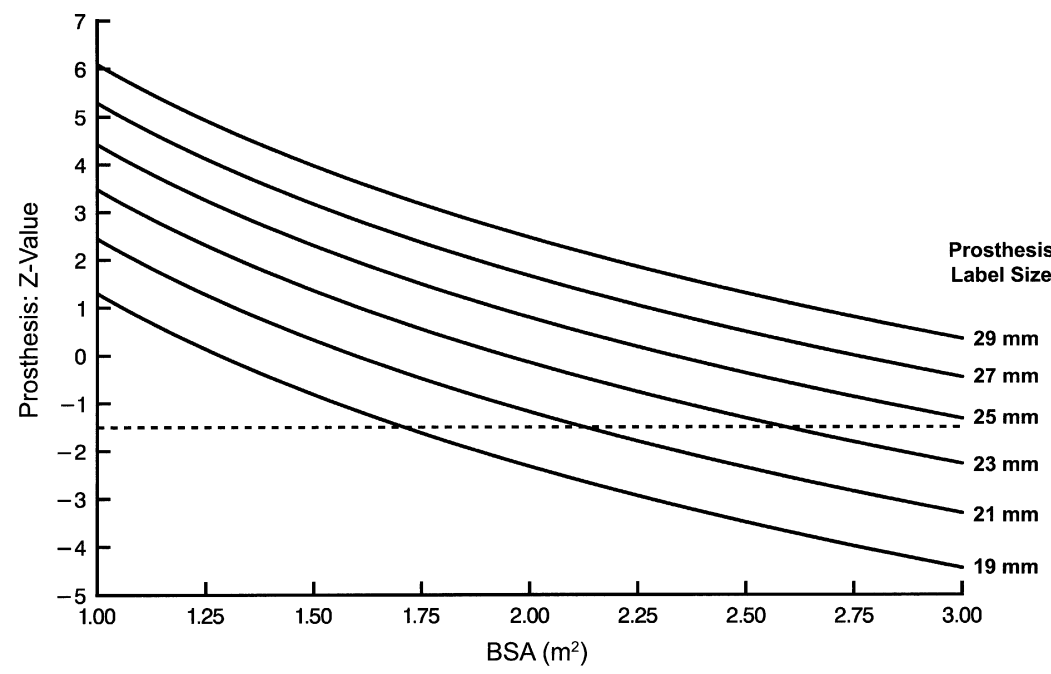

Figure E4. Nomogram for converting prosthesispatient $Z$ value and body surface area to Perimount pericardial prosthesis (Edwards Lifesciences, Irvine, Calif) label size. When a patient with a critical combination of risk factors (eg, older age and large LV mass index) is identified, use body surface area and minimum desired prosthesis-patient $Z$ value $(-1.5$, dashed horizontal line) to convert to prosthesis label size for implantation. 


\section{TABLE E1. Variables used in analyses}

\section{Demography}

Age $(\mathrm{y})$, gender, weight $(\mathrm{kg})$, height $(\mathrm{cm})$, body surface area $\left(\mathrm{m}^{2}\right)$, body mass index $\left(\mathrm{kg} / \mathrm{m}^{-2}\right)$

\section{AV stenosis}

Stenosis grade, regurgitation grade, orifice area $\left(\mathrm{cm}^{2}\right)$, mean gradient $(\mathrm{mm} \mathrm{Hg})$, peak gradient $(\mathrm{mm} \mathrm{Hg})$

\section{AV morphology}

Cusps: number of cusps, calcification, thickening, prolapse, tear, perforation, restricted cusp motion. Commissures: fused. Anulus: dilated.

\section{Symptomatology}

NYHA functional class (I-IV), emergency operation

LV geometry, function, and structure

\section{Geometry}

End-diastolic dimension $(\mathrm{cm})$, end-diastolic volume $(\mathrm{mL})$, end-diastolic volume index $\left(\mathrm{mL} / \mathrm{m}^{-2}\right)$, end-systolic dimension (cm), end-systolic volume $(\mathrm{mL})$, end-systolic volume index $\left(\mathrm{mL} / \mathrm{m}^{-2}\right)$, dilated left ventricle

\section{Function}

Fractional shortening, EF (\%), degree of LV dysfunction ( $1=$ none, $2=$ mild, $3=$ moderate, $4=$ severe)

\section{Structure}

Posterior wall thickness $(\mathrm{cm})$, intraventricular septal wall thickness $(\mathrm{cm})$, mass $(\mathrm{g})$, mass index $\left(\mathrm{g} / \mathrm{m}^{-2}\right)$

Other cardiovascular comorbidity

Ascending aorta: aneurysmal, calcified, dilated, arteriosclerosis; atrial fibrillation/flutter; ventricular arrhythmia; coronary artery disease (stenosis $\geq 50 \%$ in left main trunk, left anterior descending coronary artery system, left circumflex coronary artery system, right coronary artery system); previous myocardial infarction; other valve disease (tricuspid regurgitation, mitral regurgitation)

\section{Noncardiac comorbidity}

History of smoking, history of peripheral arterial disease, hypertension, insulin-treated diabetes, blood urea nitrogen (mg/dL ${ }^{-1}$ ), $\mathrm{creatinine}$ $\left(\mathrm{mg} / \mathrm{dL}^{-1}\right)$, creatinine clearance $\left(\mathrm{mL} / \mathrm{min}^{-1}\right)$, hematocrit $(\%)$

\section{AV prosthesis}

Label size, index size $\left(\mathrm{cm}^{2} / \mathrm{m}^{-2}\right)$, standardized size (prosthesis-patient $Z$ value)

\section{Concomitant procedure}

Coronary artery bypass grafting, internal thoracic artery graft used

Support

Aortic clamp time (minutes), cardiopulmonary bypass time (minutes)

\section{Experience}

Date of operation (years since January 1, 1991)

$A V$, Aortic valve; NYHA, New York Heart Association; $L V$, left ventricular; $E F$, ejection fraction. 
TABLE E2. Patient, procedure, and prosthesis characteristics

\begin{tabular}{|c|c|c|}
\hline Characteristic & $\mathbf{n}^{\mathrm{a}}$ & No. $(\%)$ or Mean \pm SD \\
\hline \multicolumn{3}{|l|}{ Demography } \\
\hline Age (y) & 3049 & $73 \pm 8.3$ \\
\hline Female & 3049 & $1062(35)$ \\
\hline $\mathrm{BSA}\left(\mathrm{m}^{2}\right)$ & 3044 & $1.95 \pm 0.24$ \\
\hline \multicolumn{3}{|l|}{ AV stenosis } \\
\hline Lesion & 3049 & \\
\hline Pure stenosis & & $1980(65)$ \\
\hline Mixed stenosis & & $1069(35)$ \\
\hline Pure regurgitation & & $0(0)$ \\
\hline Orifice area $\left(\mathrm{cm}^{2}\right)$ & 2540 & $0.68 \pm 0.18$ \\
\hline Mean gradient $(\mathrm{mm} \mathrm{Hg})$ & 2614 & $46 \pm 17$ \\
\hline Peak gradient $(\mathrm{mm} \mathrm{Hg})$ & 2622 & $77 \pm 27$ \\
\hline AV morphology & 3049 & \\
\hline Unicuspid & & $3(0.098)$ \\
\hline Bicuspid & & $710(23)$ \\
\hline Tricuspid & & $2335(77)$ \\
\hline Quadricuspid & & $1(0.033)$ \\
\hline \multicolumn{3}{|l|}{ Symptomatology } \\
\hline NYHA functional class & 3049 & \\
\hline I & & $408(13)$ \\
\hline II & & $1692(56)$ \\
\hline III & & $668(22)$ \\
\hline IV & & $281(9.2)$ \\
\hline Emergency operation & 3049 & $17(0.6)$ \\
\hline \multicolumn{3}{|l|}{ LV geometry, function, and structure Geometry } \\
\hline End-diastolic dimension $(\mathrm{cm})$ & 2354 & $4.8 \pm 0.85$ \\
\hline End-diastolic volume (mL) & 2354 & $114 \pm 48$ \\
\hline End-diastolic volume index $\left(\mathrm{mL} / \mathrm{m}^{-2}\right)$ & 2350 & $59 \pm 24$ \\
\hline End-systolic dimension (cm) & 2321 & $3.2 \pm 0.97$ \\
\hline End-systolic volume $(\mathrm{mL})$ & 2321 & $46 \pm 36$ \\
\hline End-systolic volume index $\left(\mathrm{mL} / \mathrm{m}^{-2}\right)$ & 2317 & $24 \pm 18$ \\
\hline \multicolumn{3}{|l|}{ Function } \\
\hline Fractional shortening & 2321 & $0.35 \pm 0.12$ \\
\hline $\mathrm{EF}(\%)$ & 2175 & $50 \pm 13$ \\
\hline Relative wall thickness (cm) & 2247 & $0.57 \pm 0.16$ \\
\hline LV dysfunction & 2696 & \\
\hline None & & $1898(70)$ \\
\hline Mild & & $232(8.6)$ \\
\hline Mild to moderate & & $76(2.8)$ \\
\hline Moderate & & $182(6.8)$ \\
\hline Moderately severe & & $149(5.5)$ \\
\hline Severe & & $159(5.9)$ \\
\hline \multicolumn{3}{|l|}{ Structure } \\
\hline Posterior wall thickness (cm) & 2270 & $1.3 \pm 0.23$ \\
\hline Intraventricular septal wall thickness $(\mathrm{cm})$ & 2315 & $1.4 \pm 0.29$ \\
\hline Mass $(g)$ & 2240 & $277 \pm 92$ \\
\hline Mass index $\left(\mathrm{g} / \mathrm{m}^{-2}\right)$ & 2236 & $142 \pm 44$ \\
\hline \multicolumn{3}{|l|}{ Other cardiovascular comorbidity } \\
\hline Ascending aorta & 3049 & \\
\hline Calcified & & $854(28)$ \\
\hline Dilated & & $409(13)$ \\
\hline Arteriosclerosis & & $697(23)$ \\
\hline Atrial fibrillation/flutter & 3049 & $201(6.6)$ \\
\hline Ventricular arrhythmia & 3049 & $317(10)$ \\
\hline
\end{tabular}


TABLE E2. Continued

\begin{tabular}{|c|c|c|}
\hline Characteristic & $n^{a}$ & No. $(\%)$ or Mean \pm SD \\
\hline Complete heart block/pacer & 3049 & $140(4.6)$ \\
\hline No. of previous non-valve cardiac operations & 3049 & \\
\hline 0 & & $2410(79)$ \\
\hline 1 & & $529(17)$ \\
\hline 2 & & $99(3.2)$ \\
\hline 3 & & $11(0.4)$ \\
\hline Presence of coronary artery disease ${ }^{b}$ & 3021 & $2022(67)$ \\
\hline LMT & 3017 & $395(13)$ \\
\hline LAD system & 3021 & $1618(54)$ \\
\hline LCx system & 3018 & $1389(46)$ \\
\hline RCA system & 3012 & $1462(48)$ \\
\hline Previous myocardial infarction & 3049 & $933(31)$ \\
\hline \multicolumn{3}{|l|}{ Noncardiac comorbidity } \\
\hline Smoking & 3011 & $1721(57)$ \\
\hline Peripheral arterial disease & 3049 & $1637(54)$ \\
\hline Hypertension & 2997 & $2140(71)$ \\
\hline Insulin-treated diabetes & 2962 & $604(20)$ \\
\hline Renal disease & 3049 & $178(5.8)$ \\
\hline BUN (mg/dL $\left.{ }^{-1}\right)$ & 2948 & $22 \pm 12$ \\
\hline Creatinine $\left(\mathrm{mg} / \mathrm{dL}^{-1}\right)$ & 2953 & $1.2 \pm 0.92$ \\
\hline Creatinine clearance $\left(\mathrm{mL} / \mathrm{min}^{-1}\right)$ & 2950 & $69 \pm 32$ \\
\hline $\mathrm{GFR}\left(\mathrm{mL} / \mathrm{min}^{-1}\right)$ & 2953 & $69 \pm 33$ \\
\hline Hematocrit $(\%)$ & 2529 & $38 \pm 5.2$ \\
\hline Bilirubin $\left(\mathrm{mg} / \mathrm{dL}^{-1}\right)$ & 2385 & $0.72 \pm 0.64$ \\
\hline \multicolumn{3}{|l|}{ AV prosthesis } \\
\hline \multicolumn{3}{|l|}{ Type } \\
\hline Carpentier-Edwards Perimount valve, model & 3049 & $3049(100)$ \\
\hline \multicolumn{3}{|l|}{2700 (Edwards Lifesciences, Irvine, Calif) } \\
\hline \multicolumn{3}{|l|}{ Label size } \\
\hline 19 & & $511(17)$ \\
\hline 21 & & $955(31)$ \\
\hline 23 & & $1076(35)$ \\
\hline 25 & & $421(14)$ \\
\hline 27 & & $78(2.6)$ \\
\hline 29 & & $8(0.3)$ \\
\hline \multicolumn{3}{|l|}{ Internal (geometric) orifice size } \\
\hline Area $\left(\mathrm{cm}^{2}\right)$ & 3049 & $1.6 \pm 0.26$ \\
\hline Area index $\left(\mathrm{cm}^{2} / \mathrm{m}^{-2}\right)$ & 3044 & $1.8 \pm 0.33$ \\
\hline Standardized ( $Z$ value) & 3044 & $-0.48 \pm 0.94$ \\
\hline \multicolumn{3}{|l|}{ Concomitant procedure } \\
\hline CABG & 3049 & $1698(56)$ \\
\hline
\end{tabular}

$A V$, Aortic valve; $B S A$, body surface area; $B U N$, blood urea nitrogen; $C A B G$, coronary artery bypass grafting; $E F$, ejection fraction; $G F R$, glomerular filtration rate; $L A D$, left anterior descending; $L C X$, left circumflex; $L M T$, left main trunk; $L V$, left ventricular; $N Y H A$, New York Heart Association; $R C A$, right coronary artery; $S D$, standard deviation. ${ }^{a}$ Data available. ${ }^{b} \geq 50 \%$ stenosis. 
TABLE E3. Patient variables associated with higher likelihood of NYHA class III or IV

\begin{tabular}{|c|c|c|c|}
\hline Variable & Coefficient \pm SD & $\boldsymbol{P}$ & Reliability $(\%)^{a}$ \\
\hline Calcified AV & $0.69 \pm 0.29$ & .02 & 72 \\
\hline Severe LV dysfunction ${ }^{b}$ & $0.39 \pm 0.071$ & $<.0001$ & 100 \\
\hline Higher grade of mitral regurgitation ${ }^{c}$ & $-0.64 \pm 0.17$ & .0002 & 94 \\
\hline Female & $0.35 \pm 0.094$ & .0002 & 85 \\
\hline Larger body mass index & $0.0303 \pm 0.0072$ & $<.0001$ & 98 \\
\hline More previous cardiac operations & $0.23 \pm 0.082$ & .005 & 67 \\
\hline More coronary artery systems diseased ${ }^{d}$ & $0.30 \pm 0.096$ & .002 & 97 \\
\hline Previous myocardial infarction & $0.34 \pm 0.095$ & .0004 & 100 \\
\hline History of renal disease & $0.33 \pm 0.16$ & .04 & 64 \\
\hline History of PAD & $0.25 \pm 0.089$ & .005 & 49 \\
\hline Lower hematocrit $^{\mathrm{e}}$ & $-0.81 \pm 0.203$ & $<.0001$ & 96 \\
\hline Earlier date of operation & $-0.069 \pm 0.013$ & $<.0001$ & 99 \\
\hline
\end{tabular}

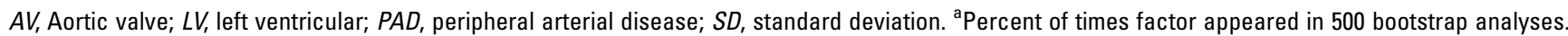
${ }^{\mathrm{b}} \mathrm{Ln}\left(\mathrm{LV}\right.$ dysfunction), logarithmic transformation. ${ }^{\mathrm{c}}(1 /$ mitral valve regurgitation +1$)$, inverse transformation. ${ }^{\mathrm{d}}$ Number of coronary artery systems diseased: 0 or 1 versus 2 or $3 .{ }^{e}(\text { Hematocrit/40) })^{2}$, squared transformation. 
TABLE E4. Patient variables associated with smaller native valve orifice area

\begin{tabular}{|c|c|c|c|}
\hline Variable & Coefficient \pm SD & $\boldsymbol{P}$ & Reliability $(\%)^{a}$ \\
\hline Older age ${ }^{b}$ & $-0.028 \pm 0.0054$ & $<.0001$ & 97 \\
\hline Lower weight $^{\mathrm{C}}$ & $-0.082 \pm 0.017$ & $<.0001$ & 99 \\
\hline Female & $-0.035 \pm 0.0085$ & $<.0001$ & 67 \\
\hline Lower grade of $\mathrm{AV}$ regurgitation & $0.014 \pm 0.0032$ & $<.0001$ & 97 \\
\hline Bicuspid morphology & $-0.018 \pm 0.008$ & .04 & 54 \\
\hline Larger LV mass index ${ }^{d}$ & $0.090 \pm 0.0013$ & $<.0001$ & 100 \\
\hline Higher grade of LV dysfunction ${ }^{\mathrm{e}}$ & $-0.033 \pm 0.0062$ & $<.0001$ & 100 \\
\hline No previous myocardial infarction & $-0.026 \pm 0.0079$ & .001 & 100 \\
\hline No LCx system stenosis ( $\geq 70 \%$ ) & $-0.045 \pm 0.0078$ & $<.0001$ & 100 \\
\hline No history of hypertension & $-0.021 \pm 0.0079$ & .008 & 88 \\
\hline No history of popliteal disease & $-0.022 \pm 0.0104$ & .03 & 60 \\
\hline Earlier date of operation & $0.0046 \pm 0.0011$ & $<.0001$ & 100 \\
\hline
\end{tabular}

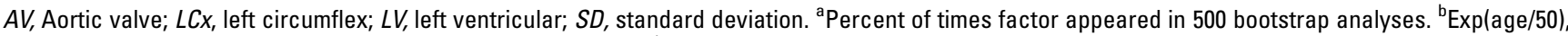
exponential transformation. ${ }^{\mathrm{c}} 80 /$ weight, inverse transformation. ${ }^{\mathrm{d}}\left(125 / \mathrm{LV}\right.$ mass index), inverse transformation. ${ }^{\mathrm{e}}$ Ln(LV dysfunction grade), logarithmic transformation. 
TABLE E5. Patient variables associated with larger preoperative left ventricular mass index

\begin{tabular}{|c|c|c|c|}
\hline Variable & Coefficient \pm SD & $\boldsymbol{P}$ & Reliability $(\%)^{a}$ \\
\hline Male & $-0.079 \pm 0.083$ & .3 & 78 \\
\hline Interaction: Male/age ${ }^{b}$ & $0.21 \pm 0.065$ & .002 & 97 \\
\hline Interaction: Female/age ${ }^{c}$ & $-0.0602 \pm 0.104$ & .6 & - \\
\hline Higher AV mean gradient ${ }^{d}$ & $0.069 \pm 0.0067$ & $<.0001$ & 100 \\
\hline Higher grade of aortic regurgitation & $0.039 \pm 0.0054$ & $<.0001$ & 100 \\
\hline NYHA functional class III/IV & $0.032 \pm 0.013$ & .02 & 70 \\
\hline Ventricular arrhythmia & $0.066 \pm 0.019$ & .0005 & 92 \\
\hline Complete heart block & $0.14 \pm 0.028$ & $<.0001$ & 100 \\
\hline History of hypertension & $0.036 \pm 0.013$ & .007 & 76 \\
\hline Higher grade of mitral regurgitation & $0.038 \pm 0.0065$ & $<.0001$ & 100 \\
\hline History of renal disease & $0.063 \pm 0.027$ & .02 & 100 \\
\hline Higher BUN ${ }^{\mathrm{e}}$ & $0.046 \pm 0.016$ & .004 & 100 \\
\hline Lower hematocrit $^{\dagger}$ & $-0.075 \pm 0.028$ & .008 & 69 \\
\hline Earlier date of operation & $-0.021 \pm 0.0019$ & $<.0001$ & 100 \\
\hline
\end{tabular}


analyses. ${ }^{\mathrm{b}} \mathrm{Male} /\left(50 /\right.$ age), inverse transformation. ${ }^{\mathrm{C}} \mathrm{Female} /(50 /$ age $)$, inverse transformation. ${ }^{\mathrm{d}}\left(\mathrm{AV}\right.$ mean gradient/45) ${ }^{2}$, squared transformation. ${ }^{\mathrm{e}} \mathrm{Ln}(\mathrm{BUN})$, logarithmic transformation. ${ }^{\mathrm{f}}(\mathrm{Hematocrit} / 40)^{2}$, squared transformation. 
TABLE E6. Patient variables associated with left ventricular dysfunction

\begin{tabular}{|c|c|c|c|}
\hline Variable & Coefficient \pm SD & $\boldsymbol{P}$ & Reliability $(\%)^{a}$ \\
\hline Smaller native AV orifice area ${ }^{b}$ & $-2.5 \pm 0.28$ & $<.0001$ & 100 \\
\hline Lower AV peak gradient & $-0.031 \pm 0.0032$ & $<.0001$ & 100 \\
\hline Larger LV end-systolic volume index & $0.094 \pm 0.0057$ & $<.0001$ & 100 \\
\hline Dilated LV & $1.1 \pm 0.202$ & $<.0001$ & 100 \\
\hline Higher grade of mitral regurgitation & $0.32 \pm 0.063$ & $<.0001$ & 99 \\
\hline Higher grade of tricuspid regurgitation ${ }^{c}$ & $-0.76 \pm 0.22$ & .0007 & 99 \\
\hline Previous myocardial infarction & $0.87 \pm 0.12$ & $<.0001$ & 99 \\
\hline LCx system stenosis ( $\geq 50 \%$ ) & $0.50 \pm 0.12$ & $<.0001$ & 85 \\
\hline Complete heart block/pacer & $0.86 \pm 0.25$ & .0006 & 67 \\
\hline Higher BUN ${ }^{\mathrm{d}}$ & $0.503 \pm 0.14$ & .0005 & 84 \\
\hline
\end{tabular}

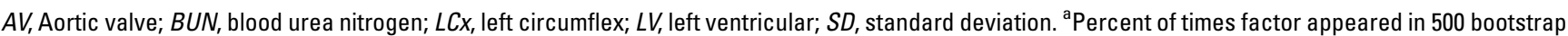
analyses. ${ }^{b} \operatorname{Ln}\left(\right.$ native AV area), logarithmic transformation. ${ }^{c}\left(1 /\left[T V\right.\right.$ regurgitation+1]), inverse transformation. ${ }^{d} \operatorname{Ln}(B U N)$, logarithmic transformation. 
TABLE E7. Patient variables associated with smaller prosthesis-patient $Z$ value

\begin{tabular}{|c|c|c|c|}
\hline Variable & Coefficient \pm SD & $\boldsymbol{P}$ & Reliability (\%) ${ }^{\mathrm{a}}$ \\
\hline Older $^{b}$ & $-1.4 \pm 0.14$ & $<.0001$ & 100 \\
\hline Female & $-0.75 \pm 0.032$ & $<.0001$ & 100 \\
\hline Smaller AV orifice area ${ }^{\mathrm{C}}$ & $0.204 \pm 0.056$ & .0003 & 85 \\
\hline Tricuspid morphology & $-0.46 \pm 0.035$ & $<.0001$ & 100 \\
\hline Smaller LV mass index & $0.0039 \pm 0.00038$ & $<.0001$ & 100 \\
\hline Complete heart blocker/pacer & $-0.15 \pm 0.067$ & .03 & 64 \\
\hline History of hypertension & $-0.084 \pm 0.032$ & .01 & 52 \\
\hline RCA system stenosis ( $>0 \%)$ & $-0.11 \pm 0.031$ & .0003 & 94 \\
\hline Treated diabetes & $-0.11 \pm 0.036$ & .003 & 88 \\
\hline Lower GFR ${ }^{d}$ & $1.5 \pm 0.073$ & $<.0001$ & 100 \\
\hline Higher creatinine clearance $\mathrm{e}^{\mathrm{e}}$ & $-1.8 \pm 0.073$ & $<.0001$ & 100 \\
\hline Earlier date of operation & $0.020 \pm 0.0044$ & $<.0001$ & 98 \\
\hline
\end{tabular}


bootstrap analyses. ${ }^{b} \mathrm{Ln}(\mathrm{age})$, logarithmic transformation. ${ }^{\mathrm{c}} \mathrm{AV}$ orifice area ${ }^{2}$, squared transformation. ${ }^{\mathrm{d}} \mathrm{Ln}(\mathrm{GFR})$, logarithmic transformation. ${ }^{\mathrm{E}} \mathrm{Ln}(\mathrm{creatinine}$ clearance), logarithmic transformation. 